08.1

\title{
Влияние металлических масок на согласование нижнего электрода с высокочастотным генератором смещения при реактивно-ионном травлении массивных подложек
}

\author{
() С.Д. Полетаев ${ }^{1,2}$, А.И. Любимов 3 \\ ${ }^{1}$ Институт систем обработки изображений РАН — филиал ФНИЦ \\ „Кристаллография и фротоника“ РАН, Самара, Россия \\ ${ }^{2}$ Самарский национальный исследовательский университет им. акад. С.П. Королева, Самара, Россия \\ ${ }^{3}$ НПО „Государственный институт прикладной оптики“, Казань, Россия \\ E-mail: sergpolet@gmail.com
}

Поступило в Редакцию 25 января 2021 г.

В окончательной редакции 12 марта 2021 г.

Принято к публикации 12 марта 2021 г.

\begin{abstract}
Теоретически и экспериментально исследовано влияние металлических масок на согласование нижнего электрода с высокочастотным генератором смещения при селективном реактивно-ионном травлении через маску массивных подложек во фреоне-14. Показано, что для масок с покрытием подложек выше $30 \%$ происходит рост реактивной составляющей мощности на расстояниях от центра, близких к радиусу подложки. Установлено отсутствие зависимости удельной реактивной мощности от толщины и типа металла масок. Экспериментально показано, что маски с любым практически значимым коэффициентом покрытия подложки, соединенные с нижним электродом через подложкодержатель, улучшают согласование, снижая коэффициент отражения по мощности.
\end{abstract}

Ключевые слова: дифракционный микрорельеф, реактивно-ионное травление, импеданс, подложкодержатель, нижний электрод.

DOI: 10.21883/PJTF.2021.11.51008.18717

В технологии микрооптики для формирования микрорельефа элементов с частотой штрихов свыше $500 \mathrm{~mm}^{-1}$ обычно применяется метод реактивно-ионного травления (РИТ), также широко распространенный в микроэлектронике [1-4]. Такие оптические элементы, как широкоапертурные дифракционные линзы, применяемые для фокусировки лазерного излучения высокой мощности, должны быть изготовлены на массивных пластинах, обеспечивающих высокую лучевую прочность [5]. В работе [6] нами было показано, что внесение массивных диэлектрических подложек в рабочую камеру установки РИТ приводит к резкому увеличению коэффициента отражения по мощности (превышающему предельное паспортное значение) для генератора высокой частоты (ГВЧ), соединенного с нижним электродом. Это означает нарушение согласования ГВЧ с нижним электродом, приводящее к резкому снижению скорости травления и невозможности дальнейшего проведения процесса. С целью поиска способов устранения этой проблемы был исследован подложкодержатель специальной конструкции. Тем не менее в работе не было рассмотрено влияние металлических масок на согласование нижнего электрода с ГВЧ. Изучение такого предположительного влияния важно, поскольку для формирования оптического микрорельефа обычно применяются металлические маски [7-10].

В настоящей работе исследуется влияние металлических масок на поверхности крупногабаритных подложек круглой формы на согласование нижнего электрода с ГВЧ в установках РИТ с привлечением численного эксперимента в программной среде Comsol Multiphysics.

В [6] подробно рассматриваются все параметры, необходимые для проведения численного эксперимента. Поэтому далее представлены лишь их основные особенности.

Для моделирования была выбрана программная среда COMSOL Multiphysics v.5.2 с подключением в проект модулей Inductive coupled plasma и AC/DC Electric current, позволяющих симулировать высокочастотный (ВЧ) индукционный разряд в камере установки с ВЧ-смещением, подаваемым на нижний электрод.

Моделирование проводилось в режиме 2D symmetry, поскольку конструкция вакуумной камеры симметрична. Размеры основных конструктивных элементов следующие: диаметр камеры $30 \mathrm{~cm}$, диаметр нижнего электрода $20 \mathrm{~cm}$, индуктор с изолятором $14 \times 5 \mathrm{~cm}$. На рис. 1 приведен вид моделируемых подложек с различным геометрическим рисунком масок, выполненных из алюминия. Подложка размещалась на нижнем электроде и имела размеры $12 \times 1.5 \mathrm{~cm}$. Расчет проводился программным модулем Frequency-Transient в интервале $10^{-8}-10^{-3} \mathrm{~s}$ для 21 значения времени, распределенных равномерно. Временной интервал определялся исходя из установления стационарного режима плазмы.

В результате моделирования были получены распределения удельной реактивной (на емкостной нагрузке) 
$a$
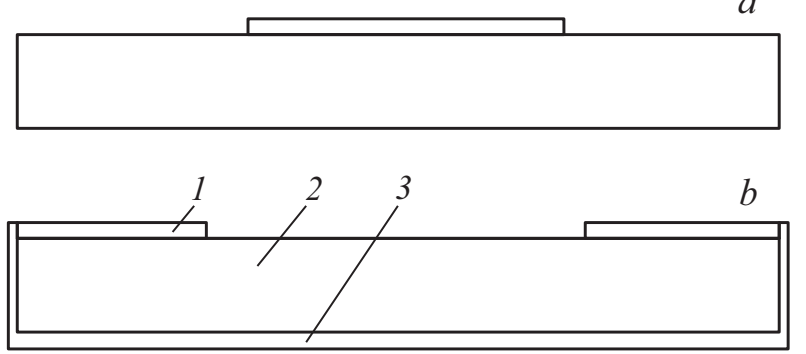

Рис. 1. Варианты моделируемых подложек с металлической маской без подложкодержателя $(a)$ и с подложкодержателем [6] (b). 1 - маска, 2 - подложка, 3 - подложкодержатель.

мощности, характеризующие коэффициент отражения по мощности для нижнего электрода.

На рис. 2, а показано расчетное распределение удельной реактивной мощности вдоль поверхности для подложек с масками, соответствующими рис. 1, $a$. Кривой 4 соответствует правая шкала. Из рисунка видно, что для подложек с покрытием маской до $30 \%$ поверхности графики выглядят одинаково. Лишь кривая 3 (коэффициент заполнения подложки маской 70\%) при $r>5.5 \mathrm{~cm}$ показывает некоторый рост мощности, достигающий приблизительно 15\% на краю подложки по сравнению с кривыми 1 и 2. Также кривые 2, 3 показывают небольшой симметричный скачок реактивной мощности на краю маски, амплитуда которого зависит от координаты края. Для подложки со 100\% заполнением маски до $r=5.8 \mathrm{~cm}$ ход кривой идентичен остальным, однако на самом краю подложки наблюдается многократный рост реактивной мощности. Для ответа на вопрос, обусловлено ли это коронным эффектом на металлическом крае, было проведено моделирование для подложки размером $6 \times 1.5 \mathrm{~cm}$ (кривая 5). Величина коронного эффекта при уменьшении радиуса подложки не должна существенно зависеть от размера подложки. Видно, что на самом краю удельная реактивная мощность для кривой 5 достигает $14 \mu \mathrm{W} / \mathrm{m}^{3}$, что почти в 6 раз меньше, чем для кривой 4. Это означает, что подложка размером $6 \times 1.5 \mathrm{~cm}$ должна вносить значительно меньшую реактивную составляющую и оказывать меньшее влияние на коэффициент отражения по мощности, а величина коронного эффекта не должна быть существенной. Вероятная причина столь сильного влияния металлической маски на удельную реактивную мощность на краю подложки заключается в характере воздействия ВЧ-потенциала нижнего электрода на поведение химически активных частиц плазмы. В этом случае маску можно рассматривать как сверхкороткий проводник большого сечения. Сечением такого проводника является его поверхность. Из электротехники известно, что ВЧ-ток протекает в поверхностном слое проводника (скин-слой). Плотность тока в скин-слое будет максимальной. В результате на краю подложки наблюдается повышенная концентрация заряженных частиц без значительного увеличения степе- ни ионизации плазмы, как это имеет место при коронном эффекте. При этом важно отметить, что в случае применения подложкодержателя [6] характер протекания ВЧ-тока будет другим. Здесь сечение проводника будет располагаться по толщине пленки.

Этой же причиной может быть объяснен разрыв кривых, наблюдаемый на границе подложки и маски. Провал графика правее границы может свидетельствовать о перераспределении заряженных частиц плазмы в ограниченном пространстве таким образом, что на краю маски будет наблюдаться их повышенная концентрация. Поскольку емкость монотонно убывает от края к центру подложки, о чем свидетельствуют графики, величина всплеска также будет убывать при перемещении границы маска-подложка в этом направлении.

На рис. 2, $b$ показана расчетная зависимость удельной реактивной мощности от коэффициента заполнения подложки маской для случая с подложкодержателем [6]. Моделирование проводилось для варианта расположения маски, соответствующего рис. $1, b$. Из рисунка видно, что ход кривых, соответствующих заполнению 30 и
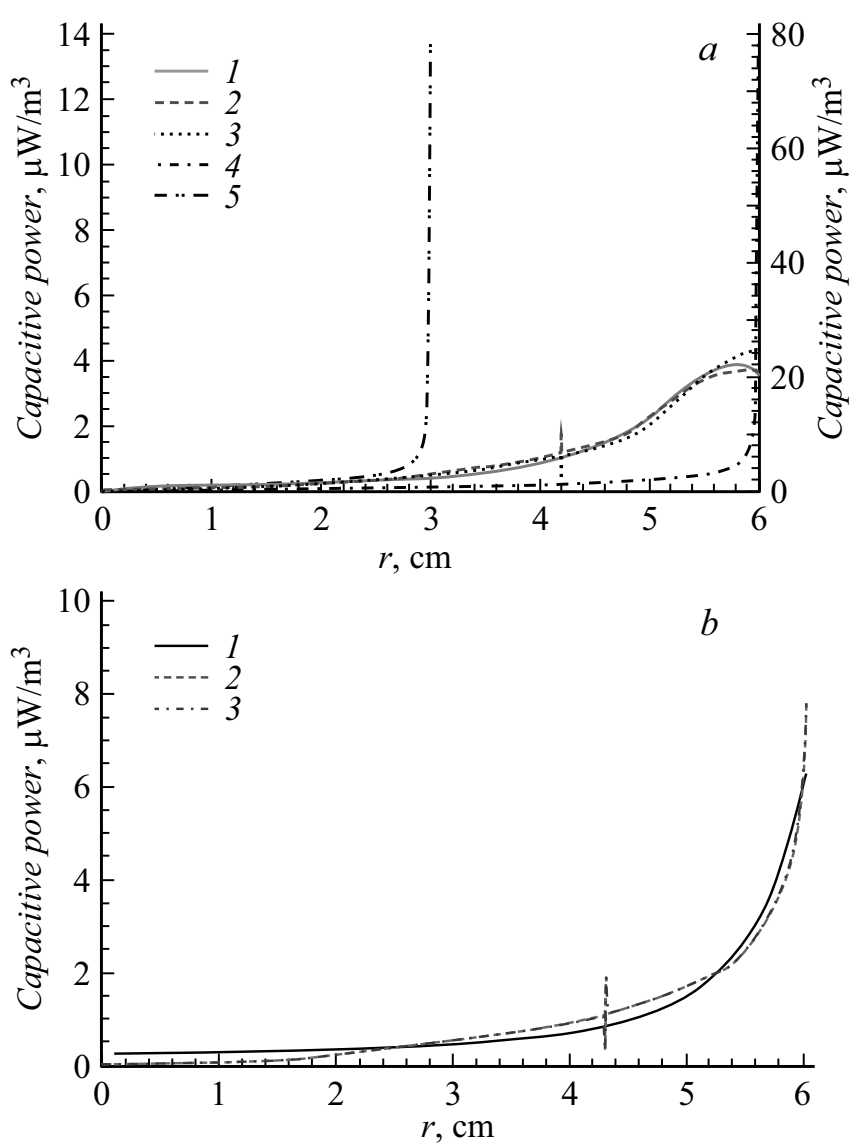

Рис. 2. Расчетное распределение удельной реактивной (на емкостной нагрузке) мощности для подложки размером $12 \times 1.5 \mathrm{~cm}$, расположенной на нижнем электроде $(a)$ и в подложкодержателе [6] $(b)$, по поверхности вдоль радиуса (относительная площадь маски, \%: $1-0,2-30,3-70$, 4 - 100). 5 - относительная площадь маски $100 \%$ для подложки размером $6 \times 1.5 \mathrm{~cm} . t=1 \mathrm{~ms}$. 
$70 \%$, идентичен. Кривая 1 , соответствующая случаю без маски, в интервале $r$ от 3 до $5.4 \mathrm{~cm}$ проходит немного ниже кривых 2 и 3 , а при $r>5.4 \mathrm{~cm}-$ немного выше (в пределах 5\%). На самом краю удельная реактивная мощность для подложек с масками приблизительно на $20 \%$ больше, чем для подложек без маски. Для данного случая неоднозначное поведение кривой 1 не позволяет провести оценку влияния маски на коэффициент отражения по мощности.

Вместе с тем кривые 2 и 3 показывают на порядок меньшие значения удельной реактивной мощности на краю подложки по сравнению со случаем без специального подложкодержателя (кривая 4 на рис. 2,a), что должно приводить к меньшим значениям коэффициента отражения по мощности.

На рис. 3 показано влияние типа металла масок и толщины алюминиевой маски на удельную реактивную мощность. Видно, что ход всех кривых на обоих рисунках идентичен. Это означает отсутствие влияния данных параметров на коэффициент отражения по мощности. Такой результат можно объяснить высокой электропроводностью металлов, что эффективно устраняет накопление заряженных частиц на поверхности подложки. При этом различия электропроводности для разных металлов несущественно влияют на данный процесс.
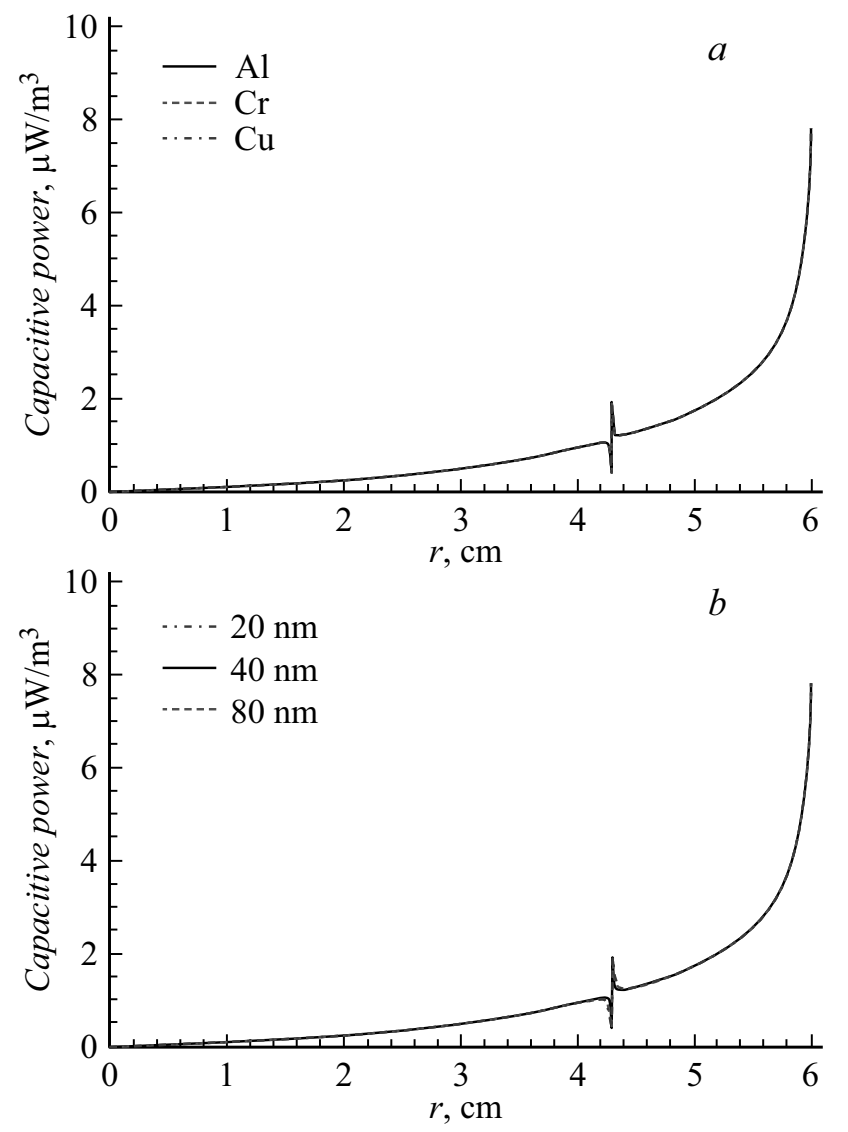

Рис. 3. Расчетное влияние типа металла масок $(a)$ и толщины алюминиевой маски $(b)$ на удельную реактивную мощность. Толщина скин-слоя алюминия $22 \mu \mathrm{m}, t=1 \mathrm{~ms}$.
Коэффициенты отражения по мощности, полученные на нижнем электроде для установки РИТ Caroline PE15 с различными газами для подложкодержателя с алюминиевой маской и без маски (мощность индуктора $400 \mathrm{~W}$, расход аргона в смеси с фреонами $0.61 / \mathrm{h}$, расход фреонов $1.01 / \mathrm{h}$, толщина маски $40 \mathrm{~nm}$ )

\begin{tabular}{c|c|c|c|c}
\hline \multirow{2}{*}{ Подложка } & \multicolumn{4}{|c}{$P_{\text {refl }} / P_{\text {inc }}, \%$} \\
\cline { 2 - 5 } & $\mathrm{CHF}_{3} / \mathrm{Ar}$ & $\mathrm{CF}_{4} / \mathrm{Ar}$ & $\mathrm{SF}_{6} / \mathrm{Ar}$ & $\mathrm{Ar}$ \\
\hline Без маски & 32 & 25 & 18 & 19 \\
С маской & 26 & 21 & 16 & 16
\end{tabular}

В таблице представлены результаты эксперимента, показывающие влияние алюминиевой маски с 70\% покрытием массивной подложки на согласование ГВЧ с нижним электродом в установке РИТ Caroline PE15 [11] в различных плазмообразующих средах. Согласование оценивалось по коэффициенту отражения падающей на электрод ВЧ-мощности от ГВЧ. Подложка размером $12 \times 1.5 \mathrm{~cm}$ устанавливалась в подложкодержатель и помещалась на нижний электрод, имеющий круглую форму диаметром $20 \mathrm{~cm}$. Расход аргона и фреонов задавался в соответствии с результатами, полученными в [6]. Ободок подложкодержателя устанавливался таким образом, чтобы его выступ находился на поверхности подложки, подвергаемой воздействию плазмы. Это обеспечивает электрический контакт маски с держателем. Для повышения надежности и равномерности контакта между выступом ободка и маской дополнительно прокладывалась фольга. Из таблицы видно, что обеспечение электрического контакта маски с нижним электродом приводит к заметному улучшению согласования. В этом случае снижение коэффициента отражения по мощности составляет в большинстве случаев до $15 \%$, а для $\mathrm{CHF}_{3}$ - около 20\%. Такой результат показывает возможность дополнительного согласования нижнего электрода с ГВЧ в установках РИТ в процессе формирования оптического микрорельефа через металлические маски.

В работе представлены теоретические и экспериментальные результаты изучения влияния металлических масок на РИТ массивных подложек в плазмообразующих газовых смесях на основе различных фреонов.

С учетом [6] можно заключить, что снижение коэффициента отражения по мощности и соответствующее улучшение согласования нижнего электрода с ГВЧ в процессе РИТ массивных подложек возможно путем применения подложкодержателя специальной конструкции как без добавки, так и с добавкой аргона в зависимости от типа плазмообразующего фреона. При этом металлические маски дополнительно снижают коэффициент отражения по мощности на 10-20\%.

Применение описанных конструкций и методик РИТ позволяет изготавливать дифракционные элементы на массивных подложках, применимых для работы в составе схем с лазерами высокой мощности видимого и УФ-диапазонов. 


\section{Финансирование работы}

Работа выполнена в рамках госзадания „Кристаллография и фотоника“" РАН (соглашение № 007-ГЗ/43363/26) и договора о НИР № 08/2017 (заказчик НПО „Государственный институт прикладной оптики““).

\section{Конфликт интересов}

Авторы заявляют, что у них нет конфликта интересов.

\section{Список литературы}

[1] А.В. Волков, Н.Л. Казанский, О.Е. Рыбаков, Компьютерная оптика, № 18, 130 (1998).

[2] M. Puttock, Surf. Coat. Technol., 97 (1-3), 10 (1997). https://doi.org/10.1016/S0257-8972(97)00281-8

[3] С.В. Михайлович, А.Ю. Павлов, К.Н. Томош, Ю.В. Федоров, Письма в ЖТФ, 44 (10), 61 (2018). DOI: 10.21883/PJTF.2018.10.46100.17227 [Пер. версия: 10.1134/S1063785018050218].

[4] R. Szweda, Technology Focus, 14 (1), 42 (2001). https://doi.org/10.1016/S0961-1290(01)89007-4

[5] N.L. Kazanskiy, G.V. Uspleniev, A.V. Volkov, Proc. of SPIE, 4316, 193 (2000). DOI: 10.1117/12.407678

[6] С.Д. Полетаев, А.И. Любимов, ЖТФ, 91 (4), 657 (2021). DOI: 10.21883/JTF.2021.04.50630.271-20

[7] D.W. Hess, Plasma Chem. Plasma Process., 2 (2), 141 (1982).

[8] A.P. Milenin, C. Jamois, R.B. Wehrspohn, M. Reiche, Microelectron. Eng., 77 (2), 139 (2005). https://doi.org/10.1016/j.mee.2004.10.001

[9] W.-T. Li, D.A.P. Bulla, R. Boswell, Surf. Coat. Technol., 201 (9-11), 4979 (2007). https://doi.org/10.1016/j.surfcoat.2006.07.083

[10] V.P. Veiko, A.G. Poleshchuk, in Fundamentals of laserassisted micro- and nanotechnologies, eds V. Veiko, V. Konov, Springer Ser. in Materials Science (Springer, Cham, 2014), vol. 195, p. 149. DOI: 10.1007/978-3-319-05987-7_7

[11] Е.В. Берлин, С.А. Двинин, Л.А. Сейдман, Вакуумная технология и оборудование для нанесения и травления тонких пленок (Техносфера, М., 2007). 